\title{
The urgent need to develop emergency EYE care in the UK: the way forward?
}

Eye (2017) 31, 1515-1518; doi:10.1038/eye.2017.113; published online 16 June 2017

\section{Introduction}

For two decades prior to 2004, a steady state existed of $\sim 14$ million general Accident and Emergency (A\&E) annual attendances in England. This total has risen each year since, with 22.9 million attendances recorded in 2015/16 (https://www.england.nhs.uk/statistics/wpcontent/uploads/sites/2/2016/06/Monthly-AEReport-December-16.pdf). Resultant pressure on $A \& E$ has received a great deal of public attention and extra resourcing with medical staff numbers rising $71 \%$ from 2002 to 2012 . $^{1}$

\section{The way forward project}

This work was commissioned by The Royal College of Ophthalmologists (RCOphth) in part to identify and disseminate innovations to deal with rising numbers of Emergency Eye Care (EEC) patients without commensurate increment in resource to meet those demands, the capacity/demand disequilibrium being further exacerbated by other factors (Figure 1). The full report is available online (www.rcophth.ac.uk) standards-publications-research/the-wayforward); this article provides a summary.

A literature review was conducted, and with many innovations not being amenable to publication, a telephone survey of consultants responsible for EEC across the UK was undertaken. Lead Clinicians from every UK eye department were emailed $(n=142)$ using the RCOphth database and asked for details of consultants responsible for EEC. Ninety-one lead clinicians responded and a total of 50 semistructured interviews completed (January to June 2016), representing 35\% of UK eye departments.
Where is the increased demand coming from?

Rising numbers of patients were reported by every consultant $(n=6)$ who had $\geq 5$-year emergency attendance data, consistent with published reports. ${ }^{2}$ Estimation of incidence of eye emergencies is presented in the joint RCOphth/College of Optometrist Urgent Eye Care Commissioning Guidance, ${ }^{2}$ however, other than emergencies strongly linked to older age such as vasculo-occlusive events or vitreous / retinal detachments, there is little reason to expect a rise in incidence. Just as in main A\&E, it is assumed that incidence is not the main driver of increasing demand, but that changes in health-seeking behaviour are pushing up attendances. To give some sense of the scale of the potential attendees that could migrate towards emergency secondary care;

- More than 430 million Pharmacists attendances in England annually for health related reasons. ${ }^{3}$

- More than 1 million bottles of over-thecounter chloramphenicol are dispensed annually. ${ }^{4}$

- 16 million optician sight tests/eye examinations performed annually in the UK. ${ }^{5}$

- 340 million GP consultations of which $1.5-2 \%$ are eye related. ${ }^{3}$

- 24 million calls made to NHS urgent telephone services. $^{3}$

If even small percentages divert to Hospital Eye Service (HES), continuation of the growth experienced in the past decade is possible.

\section{Demand management: minimising inappropriate presentations}

The consensus exists that 'there is limited scope for preventing urgent eye conditions', ${ }^{2}$ so demand reduction focuses on 'unnecessary' / 'inappropriate' attendances. ${ }^{6}$ However, working 
with a definition of appropriate as 'any eye condition that is of recent onset and is distressing or is believed by the patient, carer or referring health professional to present an imminent threat to vision or general health', ${ }^{2}$ then great caution should be exercised when labelling referrals or patient-initiated presentations as inappropriate, particularly given the great concern that eye problems arouse. ${ }^{7}$ Cases must be considered entirely appropriate, even if they ultimately transpire to be non-sight threatening or even trivial, if they were indistinguishable from serious pathology by patients or referring practitioners.

Rather than berating patients for feeling anxious or primary care colleagues for poor referrals, more should be done to empower them by engaging with training programmes, such as the Scottish 'Teach and Treat' centres, or provision of triage tools to prevent low-value attendances. ${ }^{8}$

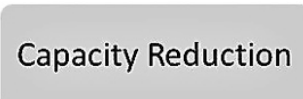

\section{Demand Growth}

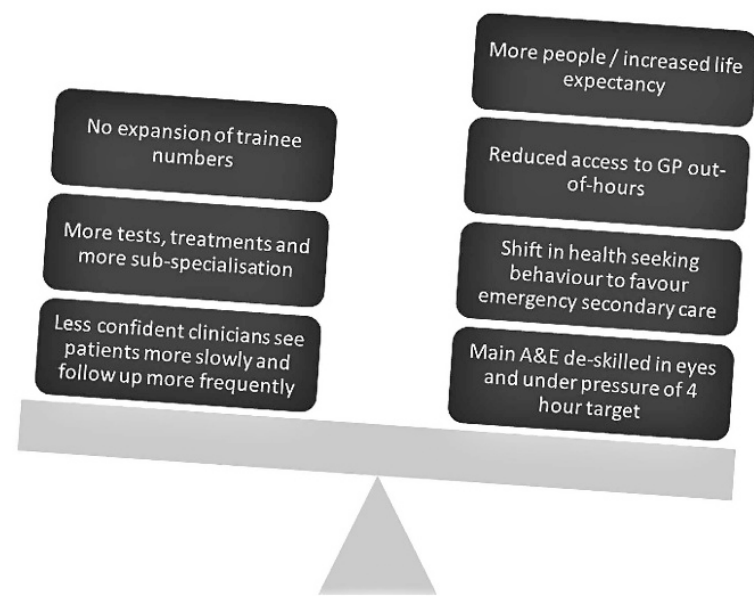

Figure 1 The capacity:demand disequilibrium.

\section{Demand management: is there a role for triage?}

Triage tools administered by patients, ${ }^{9}$ computer $^{10}$ or health care professionals have been shown to be effective, ${ }^{6,11,12}$ but the relevance of specific tools will depend on local case-mix and EEC options. ${ }^{13}$ If no alternative sources of EEC other than the HES eye casualty exists, there is less demand reduction opportunity from triaging. Where primary care EEC options and sub-specialist acute clinics are available, triage has an important role.

\section{Capacity expansion: the multi-disciplinary team}

Good clinical decision making by appropriately trained multi-disciplinary team (MDT) members such as nurse practitioners or optometrists is well documented. ${ }^{5,14-17}$ The fact that an EEC MDT can function well is beyond debate, but this does not guarantee that appropriate staff can be recruited and many interviewees reported valuable MDT members being difficult to replace on leaving.

The complexity of cases presenting to EEC services is a function of the accessibility of those services (Table 1). Walk-in services, with large proportions of lower complexity patients benefit most from MDT, usually with specialist nurses triaging and dealing with many (in some cases over half) of emergency attendees such that they never see an ophthalmologist. ${ }^{14,18,19}$ Limiting access might be expected to reduce demand, but resultant increased case-complexity reduces capacity by slowing junior doctors and reducing the role of nonophthalmologists.

\section{Capacity expansion: community optometrist services}

Community optometrists' role in eye care pathways in Wales and Scotland has been significantly expanded and clarified, but in England there is a lack of national strategic direction, so a variety of local solutions have been trialled without a proven clinically effective and cost-effective dominant model having yet emerged. ${ }^{20-22}$

Table 1 Increasingly accessible services may incite greater per capita attendances of lower complexity cases

\begin{tabular}{|c|c|c|c|c|}
\hline $\begin{array}{l}\text { Model of Emergency Service } \\
\text { Provision }\end{array}$ & $\begin{array}{l}\text { Population } \\
\text { served (mean) }\end{array}$ & $\begin{array}{l}\text { Attendances per } \\
\text { annum (mean) }\end{array}$ & $\begin{array}{l}\text { Attendances/ } \\
1,000 \text { pop./year }\end{array}$ & EEC patient characteristics \\
\hline $\begin{array}{l}\text { Slotting patients into clinics } \\
(n=3)\end{array}$ & 350000 & 3000 & 9 & $\begin{array}{l}\text { More complex patients, mostly in need of an } \\
\text { ophthalmologist }\end{array}$ \\
\hline $\begin{array}{l}\text { Acute Referral Clinics } \\
(n=33)\end{array}$ & 500000 & 7000 & 14 & $\begin{array}{l}\text { Some lower complexity patients. EEC practitioners } \\
\text { need to work at a higher level than the referring } \\
\text { clinicians }\end{array}$ \\
\hline $\begin{array}{l}\text { Daytime Walk-in Service } \\
(n=9)\end{array}$ & 760000 & 15000 & 20 & $\begin{array}{l}\text { Higher numbers of low complexity patients. Large } \\
\text { role for non-ophthalmologists }\end{array}$ \\
\hline $\begin{array}{l}\text { 24-hour Walk-in Service } \\
(n=2)\end{array}$ & 880000 & 40000 & 45 & \\
\hline
\end{tabular}


The fear is that increased accessibility will further awaken previously unmet supply-driven demand without improving population-level clinical outcomes, so there is an urgent national need to evaluate whether such schemes produce a cost-effective improvement in EEC delivery.

\section{The future of EEC}

The choice exists, therefore, to develop high-volume walk-in MDT services, or to build primary care capacity to see emergencies and reserve secondary care for higher complexity cases. The latter is likely to be appropriate in low population density areas, where relative benefits for patients in providing care closer to home are highest. Whatever is done, intentional strategic leadership is essential and better connectivity can be anticipated with electronic referral, feedback and advice. Eye casualty departments traditionally have been staffed by the least experienced trainee ophthalmologists, but this paradigm is shifting. Getting senior opinions early is improving efficiencies in A\&E and acute medical settings. ${ }^{23,24}$ Consultant-led, strategic planning of MDT-delivered services driving aspirational standards in EEC provision is anticipated to be the future of EEC in the UK.

\section{Conflict of interest}

The authors declare no conflict of interest.

\section{Acknowledgements}

The Way Forward project was commissioned and funded by The Royal College of Ophthalmologists. Subsequent salary support for JC Buchan is provided by the Queen Elizabeth Diamond Jubilee Trust. Contribution is acknowledged from the Way Forward Steering Committee and Reference Group: Tom Bremridge, Barny Foot, Richard Smith, John Somner, John Sparrow, Rachel Stancliffe, Peter Tiffin. MeSH terms-Delivery of Health Care/organization \& administration, Ophthalmology/ education, Ophthalmology/manpower, Ophthalmology/ organization and administration, Ophthalmology/trends, Eye Diseases/organization and administration, Eye Diseases/prevention and control.

\section{References}

1 www.hscic.gov.uk/catalogue/PUB13040/acci-emer-focuon-2013-rep-V2.pdf. Focus on Accident and Emergency. Health and Social Care Information Centre 2013.

2 Smith R, Tromans C. Commissioning Better Eye Care: Urgent Eye Care. Royal College of Ophthalmologists/College of Optometrists, 2013.
3 Transforming urgent and emergency care services in England. NHS England, 2013.

4 Walker R, Hinchliffe A. Prescribing and sale of ophthalmic chloramphenicol following reclassification to over-the-counter availability. Int J Pharm Pract 2010; 18(5): 269-274.

5 Parkins DJ, Curran R, Pooley JE, Ryan B. The developing role of optometrists as part of the NHS primary care team. Optom Pract 2014; 15(4): 177-184.

6 Al-Arrayedh H, O'Doherty M, Murphy C, O'Reilly F. An audit of primary care referrals to the Ophthalmic Accident and Emergency Department of the Royal Victoria Eye and Ear Hospital, Dublin. R Coll Surg Ireland Student Med J 2010; 3: 25-28.

7 Hau S, Ioannidis A, Masaoutis P, Verma S. Patterns of ophthalmological complaints presenting to a dedicated ophthalmic Accident \& Emergency department: inappropriate use and patients' perspective. Emerg Med J 2008; 25(11): 740-744.

8 Timlin H, Butler L, Wright M. The accuracy of the Edinburgh Red Eye Diagnostic Algorithm. Eye 2015; 29(5): 619-624.

9 Eijk ES, Busschbach JJ, Monteban H, Timman R, BettinkRemeijer MW. Towards patient self-triage in the ophthalmic emergency department: sensitivity and specificity of a selftriage instrument. Acta Ophthalmol 2014; 92(7): 697-700.

10 Eijk ES, Wefers Bettink-Remeijer M, Timman R, Heres MH, Busschbach JJ. Criterion validity of a computer-assisted instrument of self-triage (ca-ISET) compared to the validity of regular triage in an ophthalmic emergency department. Int J Med Inform 2016; 85(1): 61-67.

11 Rossi T, Boccassini B, Cedrone C, Iossa M, Mutolo MG, Lesnoni $\mathrm{G}$ et al. Testing the reliability of an eye-dedicated triaging system: the RESCUE. Eur J Ophthalmol 2008; 18(3): 445-449.

12 Bourges JL, Boutron I, Monnet D, Brezin AP. Consensus on severity for ocular emergency: the basic severity score for common ocular emergencies [BaSe SCOrE]. J Ophthalmol 2015; 2015: 576983.

13 Vartsakis G, Fahy G. The profile of patients attending a triaged eye emergency service. Ir J Med Sci 2014; 183(4): 625-628.

14 Buchan JC, Saihan Z, Reynolds AG. Nurse triage, diagnosis and treatment of eye casualty patients: a study of quality and utility. Accid Emerg Nurs 2003; 11(4): 226-228.

15 Banerjee S, Beatty S, Tyagi A, Kirkby GR. The role of ophthalmic triage and the nurse practitioner in an eyededicated casualty department. Eye 1998; 12(Pt 5): 880-882.

16 Kirkwood BJ, Pesudovs K, Loh RS, Coster DJ. Implementation and evaluation of an ophthalmic nurse practitioner emergency eye clinic. Clin Exp Ophthalmol 2005; 33(6): 593-597.

17 Hau S, Ehrlich D, Binstead K, Verma S. An evaluation of optometrists' ability to correctly identify and manage patients with ocular disease in the accident and emergency department of an eye hospital. Br J Ophthalmol 2007; 91(4): 437-440.

18 Jones NP, Hayward JM, Khaw PT, Claoue CM, Elkington AR. Function of an ophthalmic "accident and emergency" department: results of a six month survey. Br Med J 1986; 292 (6514): 188-190.

19 Buchan JC, Ashiq A, Kitson N, Dixon J, Cassels-Brown A, Bradbury JA. Nurse specialist treatment of eye emergencies: five year follow up study of quality and effectiveness. Int Emerg Nurs 2009; 17(3): 149-154.

20 Sheen NJ, Fone DL, Phillips CJ, Sparrow J, Pointer JS, Wild J. Novel Optometrist-led all Wales primary eye-care services: 
evaluation of a prospective case series. Br J Ophthalmol 2009; 93(4): 435-438.

21 Baker H, Ratnarajan G, Harper RA, Edgar DF, Lawrenson JG. Effectiveness of UK optometric enhanced eye care services: a realist review of the literature. Ophthalmic Physiol Opt 2016; 36(5): 545-557.

22 Konstantakopoulou E, Edgar DF, Harper RA, Baker H, Sutton M, Janikoun $\mathrm{S}$ et al. Evaluation of a minor eye conditions scheme delivered by community optometrists. BMJ Open 2016; 6(8): e011832.

23 Bell D, Lambourne A, Percival F, Laverty AA, Ward DK. Consultant input in acute medical admissions and patient outcomes in hospitals in England: a multivariate analysis. PLoS One 2013; 8(4): e61476.

24 Christmas E, Johnson I, Locker T. The impact of $24 \mathrm{~h}$ consultant shop floor presence on emergency department performance: a natural experiment. Emerg Med J 2013; 30(5): 360-362.

JC Buchan1, B Barnes², A Cassels-Brown³, BY Chang ${ }^{4}$, $\mathrm{J} \mathrm{Harcourt}^{5}$, RF Pilling ${ }^{6}$, D Shickle ${ }^{7}$, AF Spencer ${ }^{8}$, SA Vernon ${ }^{9}$ and $C$ MacEwen ${ }^{10}$

${ }^{1}$ International Centre for Eye Health, London School of Hygiene and Tropical Medicine, London, UK
${ }^{2}$ The Royal College of Ophthalmologists, London, UK

${ }^{3}$ Department of Ophthalmology, St James's University

Hospital, Leeds, UK

${ }^{4}$ Department of Ophthalmology, St James's University

Hospital, Leeds, UK

${ }^{5}$ Eye Department, Aberdeen Royal Infirmary,

Forresterhill, Aberdeen, UK

${ }^{6}$ Department of Ophthalmology, Bradford Royal

Infirmary, Duckworth Lane, Bradford, UK

${ }^{7}$ Leeds Institute of Health Sciences, Level 10, University of Leeds, Clarendon Way, Leeds, UK

${ }^{8}$ Manchester Royal Eye Hospital, Manchester, UK

${ }^{9}$ The BMI Park Hospital, Sherwood Lodge Drive,

Arnold, Nottingham, UK

${ }^{10}$ Ward 25, Ninewells Hospital, Dundee, UK

Correspondence: Dr JC Buchan, International Centre for Eye Health, Keppel Street, London WC1E 7HT, UK

Tel: +44 200113 2433144;

Fax: +44 2001132066044 .

E-mail: john.buchan@lshtm.ac.uk 